\title{
Author's Reply to the Letter to Editor, "Transarterial Embolization Followed by Percutaneous Vertebroplasty in Treating Vertebral Metastases with Paravetebral Extension"
}

\section{To THE EDITOR:}

We appreciate and would like to thank Zhen Zhong Sun and Xuming Wei for their valuable and thoughtful comments after their thorough critical review of our paper "Sequential transarterial embolization followed by percutaneous vertebroplasty is safe and effective in pain management in vertebral metastases" (1). We would like to respond to the letter as follows.

We agree with their suggestion that postoperative computed tomography (CT) should be performed to confirm whether there is shrinkage of the paravertebral lesion or tumor recurrence, which is helpful to find out the mechanism of pain change. We have already found the phenomenon of shrinkage of the paravertebral lesion or tumor after transarterial embolization and percutaneous vertebroplasty (PVP) procedures with $\mathrm{CT}$, and we are collecting materials to form a paper.

Zhenzhong Sun and Xuming Wei also argued: "The pain relief after PVP was not only related to the reinforcement of the vertebral body by bone cement, but also to the chemical and thermal effects, which may damage the sensory nerve endings and kill the tumor cells" (2). "In addition, the space occupying effect of bone cement may inhibit tumor cell growth" (3). "Therefore, to prevent local recurrence, we suggest that the destructive area should be filled with cement as much as possible and the normal area should also be augmented." We completely agree with their views. So we emphasize the satisfactory cement distribution during the PVP procedure.

Finally, we would like to thank Zhen Zhong Sun and Xuming Wei again for their valuable and thoughtful comments and suggestions.

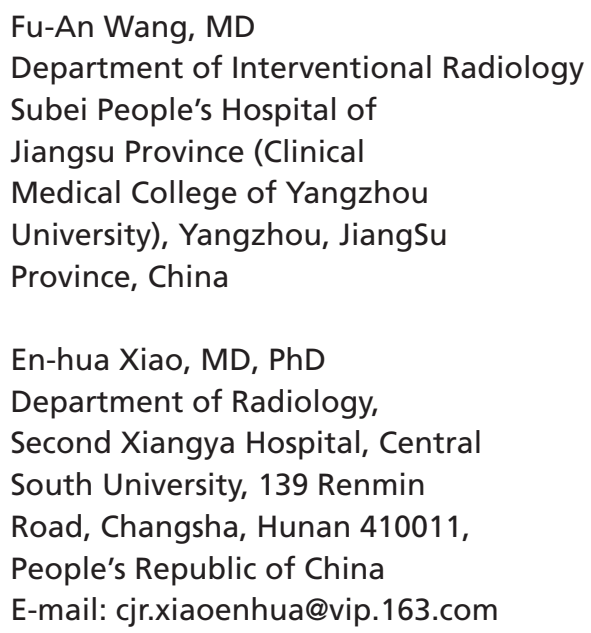

\section{References}

1. Wang FA, He SC, Xiao EH, Wang SX, Sun L, Lv PH, Huang WN. Sequential transarterial embolization followed by percutaneous vertebroplasty is safe and effective in pain management in vertebral metastases. Pain Physician 2016; 19: E559-E567.
2. Chen L, Ni RF, Liu SY, Liu YZ, Jin YH, 3. Zhu XL, Zou JW, Xiao XS. Percutaneous vertebroplasty as a treatment for painful osteoblastic metastatic spinal lesions. J Vasc Interv Radiol 2011; 22:525-528.
Yang HL, Sun ZY, Wu GZ, Chen KW, Gu Y, Qian ZL. Do vertebroplasty and kyphoplasty have an antitumoral effect? Med Hypotheses 2011; 76:145-146. 